\title{
miR-183 and miR-141 in lesion tissues are potential risk factors for poor prognosis in patients with infected abdominal aortic aneurysm
}

\author{
CHUNYING MENG ${ }^{1}$, ZEHENG GUO ${ }^{2}$, DAGANG LI ${ }^{1}$, HANWEI LI ${ }^{1}$,

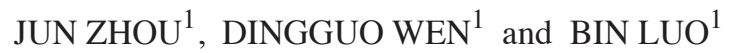 \\ ${ }^{1}$ Department of Cardiovascular Surgery, Jinan University 2nd Clinical Medicine College \\ People's Hospital of Shenzhen, Shenzhen, Guangdong 518020; ${ }^{2}$ Out-patient Department, Futian District \\ Maternal and Child Health Hospital of Shenzhen City, Shenzhen, Guangdong 518045, P.R. China
}

Received November 16, 2017; Accepted September 4, 2018

DOI: $10.3892 / \mathrm{etm} .2018 .6733$

\begin{abstract}
The expression levels of micro ribonucleic acid-183 (miR-183) and miR-141 in the lesion tissues of infected abdominal aortic aneurysm (IAAA) and their relationship with prognosis were investigated. Thirty-six patients with IAAA admitted and who underwent vascular surgery in People's Hospital of Shenzhen from June 2003 to June 2013 were selected. Reverse transcription polymerase chain reaction (RT-PCR) was utilized to detect the expression levels of miR-183 and miR-141 in lesion tissues and adjacent tissues $1 \mathrm{~cm}$ away from the aneurysm in 36 patients with IAAA. The relationship between the expression levels of miR-183 and miR-141 as well as the clinicopathological features of patients with IAAA were analyzed, and the factors influencing the prognosis of IAAA were analyzed by univariate and multivariate analysis. The expression levels of miR-183 and miR-141 were significantly downregulated in the lesions of patients with IAAA, and miR-183 and miR-141 levels in the lesion tissues of the IAAA patients were significantly lower than those in the adjacent tissues $(\mathrm{P}<0.05)$. The expression levels of miR-183 and miR-141 were not related to sex, age, history of hypertension, and alcoholism $(\mathrm{P}>0.05)$, but they were related to smoking history or aneurysm size $(\mathrm{P}<0.05)$. The overall survival rate of patients with IAAA was $41.6 \%(15 / 36)$. The multivariate analysis found that aneurysm size, low expression of miR-183, and low expression of miR-141 were independent factors affecting the prognosis of patients with IAAA. In conclusion, the expression levels of miR-183 and miR-141 in the lesion tissues of IAAA are low, and the lower the expression level
\end{abstract}

Correspondence to: Dr Zeheng Guo, Out-patient Department, Futian District Maternal and Child Health Hospital of Shenzhen City, 1019 Jintian South Road, Futian, Shenzhen, Guangdong 518045, P.R. China

E-mail: gnk8yy@163.com

Key words: miR-183, miR-141, IAAA, prognosis, RT-PCR is, the worse the prognosis gets. miR-183 and miR-141 can be used as predictors of prognosis in patients with IAAA.

\section{Introduction}

Infected abdominal aortic aneurysm (IAAA) is a special type of abdominal aortic aneurysm (AAA), accounting for $0.7-3.0 \%$ of all AAA (1), and approximately $1-3 \%$ of infected aneurysms (2). The disease is not easy to be found in the early stage, and the missed diagnosis and misdiagnosis rate is high. Once the rupture occurs, it risks the lives of patients directly and brings huge economic burden to the patients as well as their families. In some developed countries, the screening of high-risk population of IAAA may effectively increase the survival rate of patients (3-5). At present, the main molecular mechanism of IAAA has not yet been identified, and most scholars believe that the disease is caused by genetic, inflammation and other factors.

Micro ribonucleic acids (miRNAs) are a class of endogenous, non-coding small molecule RNA, which regulate the expression of target genes by inhibiting or promoting the lysis of messenger RNA (mRNA) through specific translation of sequences, resulting in the different impacts of biological behavior of tumors (6). Many studies have found that miRNA is expressed in other cancers and diseases. miRNA-141 (miR-141), a member of the miRNA-200 family, plays an important role in the occurrence, development and physiological status of diseases by regulating different signaling pathways (7). Research has shown that (8) miR-141 is closely related to tumor and angiogenesis. In the study of Liu et al (9), through the analysis of 7 GEO chips, it was found that miR-141 was differentially expressed in the tissues of liver cancer patients. miRNA-183 (miR-183), located on human 7q32.2 chromosome, is one of the most important members of the miR-183 family. In addition, research has shown that miR-183 is closely related to tumor occurrence and recurrence (10). The study of Fan et al (11) has shown that the differential expression of miR-183 in breast cancer patients was found through the analysis of GEO (GSE39093) chip. However, it is not clear whether miR-141, miR-183 and IAAA are related. 
Some studies have shown that $(12,13)$ miR-183 and miR-141 are highly expressed in TB patients, while TB bacillus, as the main pathogenic microorganism of IAAA, has not been reported in relevant studies before. The relationship between miR-183, miR-141 and clinicopathological characteristics as well as follow-up data were studied by detecting the expression levels of miR-141 and miR-183 in IAAA to explore whether miR-183 and miR-141 were potential risk factors for the poor prognosis of patients with IAAA.

\section{Patients and methods}

Sample source. Thirty-six patients with IAAA admitted and who received vascular surgery in People's Hospital of Shenzhen (Shenzhen, China) from June 2003 to June 2013 were collected and selected, the average age of the patients was $41 \pm 16.1$ years, and they were diagnosed with IAAA by computerized tomography (CT) scanning and abdominal magnetic resonance imaging (MRI) in the imaging department of the hospital. There were 20 male patients and 16 female patients. The samples and adjacent tissues $1 \mathrm{~cm}$ away from the aneurysm collected from surgical resection were stored in liquid nitrogen within $5 \mathrm{~min}$. None of the patients received radiotherapy, chemotherapy or other anticancer therapies before operation. The study was approved by the Ethics Committee of People's Hospital of Shenzhen, and the family members and patients were informed and signed the informed consent form.

Reagents and main equipment. TRIzol reagent and miRNA reverse transcriptase kit were purchased from Invitrogen; Thermo Fisher Scientific, Inc. (Waltham, MA, USA); SYBR Green Master Mix (Applied Biosystems; Thermo Fisher Scientific, Inc.) and ABI Prism 7900PCR instrument was purchased from Applied Biosystems; Thermo Fisher Scientific, Inc., and the reverse transcription primers and internal reference primers were synthesized by Shanghai Biological Engineering Co. Ltd. (Shanghai, China).

RNA extraction. The extraction procedure of the total RNA from the collected aneurysm and adjacent tissues by TRIzol reagent was carried out according to the instructions. The concentration and purity of the extracted RNA were detected by ultraviolet spectrophotometer (Bio Rad, Hercules, CA, USA), and the integrity of RNA was detected by agarose gel electrophoresis.

Synthesis of complementary deoxyribonucleic acid (cDNA). The miRNAs of the total RNA were reversely transcribed to synthesize cDNA following the instructions of the miRNA reverse transcription kit. The reverse transcription conditions of miRNA-183 and miRNA-141 were as follows: $37^{\circ} \mathrm{C}$ for $30 \mathrm{~min}$, and then $95^{\circ} \mathrm{C}$ for $3 \mathrm{~min}$. The synthesized cDNA solution was stored at $-20^{\circ} \mathrm{C}$.

Detection of expression levels of miRNA-183 and miRNA-141 via reverse transcription polymerase chain reaction (RT-PCR). BI Prism 7900 PCR instrument was used for PCR. The reaction system was $25 \mu \mathrm{l}$, including $12 \mu \mathrm{l} \mathrm{SYBR}$ Green Master Mix, $3 \mu \mathrm{l}$ of 10X miRNA specific primers, $2.5 \mu \mathrm{l}$ 10X universal primer, $2.5 \mu \mathrm{l}$ diluted cDNA, and RNase-free double distilled water was added up to $25 \mu 1$. For miRNA-183, upstream primer: 5'-CGTTGGATTCCTATGGCACTGGT-3' and downstream primer: 5'-TTCAAGCAGGGTCCGAGGTATTC-3'; for miRNA-141, upstream primer: 5'-TTCCGATGGCGTAA CACTGTCTG-3' and downstream primer: 5'-TTCAAGC AGGGTCCGAGGTATTC-3'; the reaction conditions were as follows: $95^{\circ} \mathrm{C}$ for $5 \mathrm{~min}, 95^{\circ} \mathrm{C}$ for $30 \mathrm{sec}, 60^{\circ} \mathrm{C}$ for $45 \mathrm{sec}$, and $72^{\circ} \mathrm{C}$ for $45 \mathrm{sec}$; a total of 40 cycles. U6 was used as reaction internal reference. All samples were repeated in 3 wells, and the results were analyzed by $2^{-\Delta \Delta \mathrm{Cq}}$ method (14).

Statistical analysis. These experimental data were analyzed by Statistical Product and Service Solutions (SPSS) 19.0 software package (IBM Corp., Armonk, NY, USA), measurement data were expressed as mean \pm standard deviation, enumeration data were tested by $\chi^{2}$ test, data between groups were compared by the independent sample Student's t-test and survival data were analyzed by Cox regression analysis. $\mathrm{P}<0.05$ suggested that the difference was statistically significant.

\section{Results}

Expression levels of miRNA-183 and miRNA-141 in IAAA tissues and adjacent tissues. Detection of tissues in 36 patients with IAAA by RT-qPCR revealed that the relative expression levels of RNA-183 and miRNA-141 in IAAA tissues were significantly lower compared to those in the adjacent tissues, and the difference was statistically significant $(\mathrm{P}<0.05)($ Fig. 1).

Analysis of correlation between IAAA clinical factors and expression levels of miRNA-183 and miRNA-141. Through the expression levels of miRNA-183 and miRNA-141 and clinicopathological features, we found that there was no statistical significance $(\mathrm{P}>0.05)$ between the expression levels of miR-183 and miR-141 and sex, age, history of hypertension or alcoholism, but there was statistical significance in patients with smoking history and aneurysm size $(\mathrm{P}<0.05)$ (Table I).

Cox regression survival analysis. In this experiment, the 3-year overall survival rate after surgery of 36 patients was $41.6 \%$ $(15 / 36)$. Univariate analysis of the collected clinicopathological features found that sex, age, history of hypertension, alcoholism, smoking history, and aneurysm location were not related to prognosis $(\mathrm{P}>0.05)$, but low expression of miR-183, low expression of miR-141, and aneurysm size in patients were significantly related to prognosis (Table II). The results of subsequent Cox multivariate analysis showed that low expression of miR-183 [hazard ratio $(\mathrm{HR})=3.587,95 \%$ confidence interval (95\% CI): 2.641-6.541, $\mathrm{P}=0.014]$ and low expression of miR-141 (HR=3.841 95\% CI: 2.894-5.981, $\mathrm{P}=0.016)$ could be used as independent prognostic factors for survival rate (Table III).

\section{Discussion}

The current traditional therapy for IAAA is surgical operation, including local excision of aneurysm tissues, debridement at a large area, and then vascular reconstruction in the outside bypass of in situ disease (13). However, IAAA patients have 

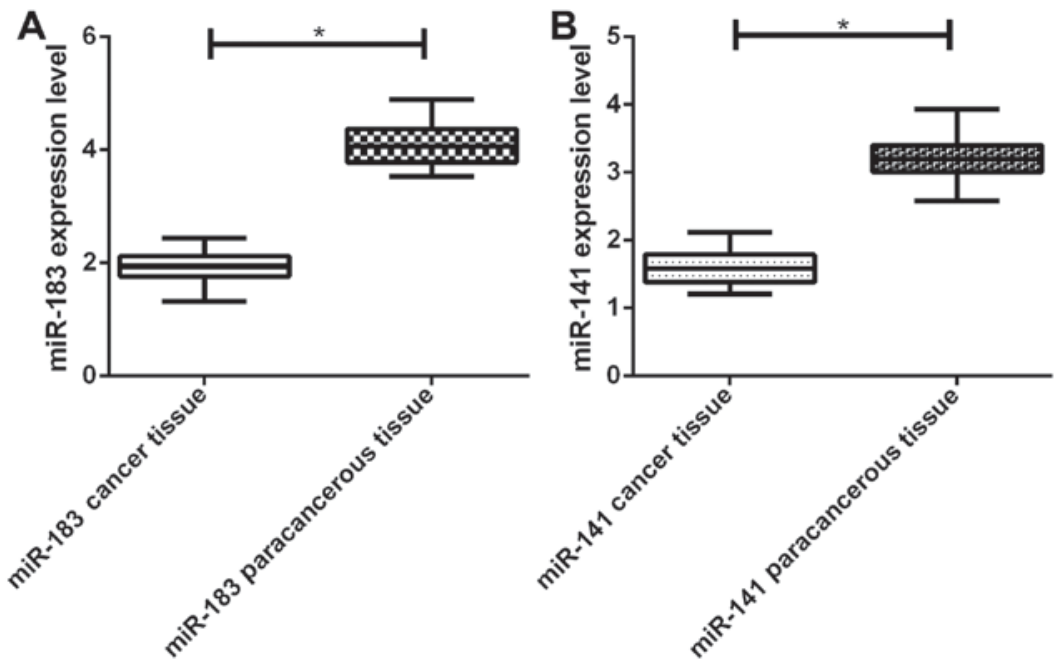

Figure 1. The expression levels of miRNA-183 and miRNA141 and their adjacent tissues. (A) The expression levels of miRNA-183 in aneurysm tissues was lower than that of adjacent tissues. ${ }^{*} \mathrm{P}<0.05$. (B) The expression levels of miRNA-141 in aneurysm tissues was lower than that of adjacent tissues. ${ }^{*} \mathrm{P}<0.05$.

Table I. Analysis of clinical factors of IAAA and expression levels of miRNA-183 and miRNA-141.

\begin{tabular}{|c|c|c|c|c|c|c|c|}
\hline Groups & $\mathrm{n}$ & $\begin{array}{c}\text { Expression level } \\
\text { of miRNA-183 }\end{array}$ & $\chi^{2}$ value & P-value & $\begin{array}{l}\text { Expression level } \\
\text { of miRNA-141 }\end{array}$ & $\chi^{2}$ value & P-value \\
\hline Sex & & & 1.331 & 0.267 & & 0.224 & 0.755 \\
\hline Male & 20 & $1.825 \pm 0.417$ & & & $1.247 \pm 0.389$ & & \\
\hline Female & 16 & $1.617 \pm 0.674$ & & & $1.384 \pm 0.247$ & & \\
\hline Age & & & 0.354 & 0.651 & & 0.574 & 0.511 \\
\hline$\geq 55$ & 17 & $1.687 \pm 0.644$ & & & $1.174 \pm 0.217$ & & \\
\hline$<55$ & 19 & $1.715 \pm 0.347$ & & & $1.089 \pm 0.373$ & & \\
\hline History of hypertension & & & 2.219 & 0.212 & & 0.667 & 0.493 \\
\hline Yes & 21 & $1.574 \pm 0.734$ & & & $1.294 \pm 0.241$ & & \\
\hline No & 15 & $1.674 \pm 0.684$ & & & $1.188 \pm 0.299$ & & \\
\hline Alcoholism & & & 0.063 & 0.497 & & 0.684 & 0.572 \\
\hline Yes & 16 & $1.674 \pm 0.774$ & & & $1.177 \pm 0.244$ & & \\
\hline No & 20 & $1.578 \pm 0.627$ & & & $1.341 \pm 0.274$ & & \\
\hline Smoking history & & & 0.184 & 0.577 & & 0.441 & 0.617 \\
\hline Yes & 20 & $1.684 \pm 0.547$ & & & $1.147 \pm 0.379$ & & \\
\hline No & 16 & $1.841 \pm 0.454$ & & & $1.214 \pm 0.214$ & & \\
\hline Tumor size & & & 4.513 & 0.031 & & 3.847 & 0.042 \\
\hline$\geq 10 \mathrm{~mm}$ & 22 & $1.324 \pm 0.241$ & & & $0.841 \pm 0.102$ & & \\
\hline$<10 \mathrm{~mm}$ & 14 & $1.784 \pm 0.404$ & & & $1.347 \pm 0.341$ & & \\
\hline
\end{tabular}

a sudden onset of disease, and the majority of patients are admitted to hospital due to rupture of aneurysm and hemorrhage. As the condition is relatively serious and there are a variety of complications, the disease is difficult to treat with traditional surgery. The mortality rate during operation is high and the survival rate is not ideal (15).

miRNAs have been found closely related to the occurrence, development, invasion and metastasis of tumors. They are a kind of molecular biological target. miRNAs match the target by the principle of complementary base pairing to degrade the target mRNA and inhibit the translation process to achieve the target gene differential expression $(6,16,17)$. Therefore, to the best of our knowledge, we studied the expression of miRNA in IAAA patients for the first time, hoping to explore the expression of miRNAs and adverse prognosis in IAAA patients.

miRNA-183 is a member of the miRNA-183 family (mainly including miRNA-183, miRNA-182 and miRNA-96), located on the human 7q32.3 chromosome, involved in the occurrence and development of a variety of tumors and closely related to their physiological processes $(18,19)$. miRNA-141 is a member of the miRNA-200 family, which plays a major role in the stable direction of epithelial cells. When the expression disorders occur, it leads to cell epithelial-mesenchymal transition increase, resulting in proliferation and metastasis 
Table II. Univariate analysis.

\begin{tabular}{lcc}
\hline & \multicolumn{2}{c}{ Single factor } \\
\cline { 2 - 3 } Factors & HR $(95 \% \mathrm{CI})$ & P-value \\
\hline Age & $1.541(1.122-3.895)$ & 0.062 \\
Sex & $1.714(1.399-1.654)$ & 0.788 \\
History of hypertension & $0.813(0.375-1.727)$ & 0.174 \\
Alcoholism & $2.143(1.288-2.755)$ & 0.034 \\
Smoking history & $1.241(0.355-2.943)$ & 0.237 \\
Tumor size & $2.064(1.282-5.723)$ & 0.064 \\
Low expression of miR-183 & $2.124(1.557-4.479)$ & 0.002 \\
Low expression of miR-141 & $2.315(1.231-3.524)$ & 0.004 \\
\hline
\end{tabular}

Table III. Multivariate analysis.

\begin{tabular}{lcc}
\hline & \multicolumn{2}{c}{ Multiple factor } \\
\cline { 2 - 3 } Factors & HR $(95 \% \mathrm{CI})$ & P-value \\
\hline Tumor size & $0.974(0.384-1.894)$ & 0.074 \\
Low expression of miR-183 & $3.587(2.641-6.541)$ & 0.014 \\
Low expression of miR-141 & $3.841(2.894-5.981)$ & 0.016 \\
\hline
\end{tabular}

of epithelial tumors $(20,21)$. This study on the detection of the expression levels of miRNA-183 and miRNA-141 in aneurysm and adjacent tissues in 36 cases of IAAA patients revealed that the expression of miRNA-183 and miRNA-141 in IAAA patients was low, and compared with the expression levels in the adjacent tissues, there was statistical significance $(\mathrm{P}<0.05)$. This may indicate that these two kinds of miRNA are associated with the clinicobiological behavior of IAAA patients. The downregulation of miRNA-183 expression in hepatocellular carcinoma is mentioned in the study of Li et al (22), and the downregulation of miRNA-141 in gastric cancer is also noted by Du et al (23), which may indicate that different miRNAs have the same expression in different cancers. The correlation analysis of the clinical factors of IAAA patients showed that there was no statistical significance between the expression of miR-183 and miR-141 and sex, age, history of hypertension, alcoholism or aneurysm location $(\mathrm{P}>0.05)$, but there was statistical significance in patients with smoking history, and the aneurysm size $(\mathrm{P}<0.05)$. Finally, Cox regression analysis showed the low expression levels of miRNA-183 and miRNA-141 could be used as independent prognostic factors for IAAA patients The main treatments of IAAA are antibiotic therapy and thorough debridement for in situ vascular reconstruction. However, as the course and the causes of IAAA are not clear at present, the location of the lesions is deep and the adjacent organs are difficult to handle when they are affected, resulting in the rupture of the aneurysm, which is mostly fatal (24). Therefore, we detected miRNA in IAAA patients and found better detection methods through this study to prevent the occurrence of the disease.
However, this study has certain limitations. As samples were difficult to collect and the number of samples was small, there was bias on the results, and there were also differences among different races. The current clinical trials are not sufficient on this subject. We hope to increase the collection of samples and increase animal experiments to support our results in future studies.

Collectively, miRNA is related to the occurrence and development of IAAA, but specific impact needs to be proven by test and study in the future. The results of this study indicate that downregulation of miRNA-183 and miRNA-141 is one of the pathogenesis of IAAA patients, and the lower the expression level is, the worse the prognosis gets, which can be used as a marker of prognosis in patients with IAAA. Thus, a new method is provided for the detection of IAAA, laying the foundation for future study of IAAA patients.

\section{Acknowledgements}

Not applicable.

\section{Funding}

No funding was received.

\section{Availability of data and materials}

The datasets used and/or analyzed during the present study are available from the corresponding author on reasonable request.

\section{Authors' contributions}

$\mathrm{CM}$ and ZG conceived and designed the study. CM, DL, HL and $\mathrm{JZ}$ were responsible for the collection and analysis of the data. CM, DW and BL interpreted the data and drafted the manuscript. ZG and DL revised the manuscript critically for important intellectual content. All authors read and approved the final manuscript.

\section{Ethics approval and consent to participate}

The study was approved by the Ethics Committee of People's Hospital of Shenzhen (Shenzhen, China). Signed informed consents were obtained from the patients or the guardians.

\section{Patient consent for publication}

Not applicable.

\section{Competing interests}

The authors declare that they have no competing interests.

\section{References}

1. Maeda H, Umezawa H, Goshima M, Hattori T, Nakamura T, Umeda $\mathrm{T}$ and Shiono M: Primary infected abdominal aortic aneurysm: Surgical procedures, early mortality rates, and a survey of the prevalence of infectious organisms over a 30-year period. Surg Today 41: 346-351, 2011. 
2. Laser A, Baker N, Rectenwald J, Eliason JL, Criado-Pallares E and Upchurch GR Jr: Graft infection after endovascular abdominal aortic aneurysm repair. J Vasc Surg 54: 58-63, 2011.

3. Greenhalgh RM, Brown LC, Powell JT, Thompson SG, Epstein D and Sculpher MJ; United Kingdom EVAR Trial Investigators: Endovascular versus open repair of abdominal aortic aneurysm. N Engl J Med 362: 1863-1871, 2010.

4. Moll FL, Powell JT, Fraedrich G, Verzini F, Haulon S, Waltham M, van Herwaarden JA, Holt PJ, van Keulen JW, Rantner B, et al; European Society for Vascular Surgery: Management of abdominal aortic aneurysms clinical practice guidelines of the European society for vascular surgery. Eur J Vasc Endovasc Surg 41 (Suppl 1): S1-S58, 2011.

5. Moulakakis KG, Dalainas I, Mylonas S, Giannakopoulos TG, Avgerinos ED and Liapis CD: Conversion to open repair after endografting for abdominal aortic aneurysm: A review of causes, incidence, results, and surgical techniques of reconstruction. J Endovasc Ther 17: 694-702, 2010.

6. Mestdagh P, Hartmann N, Baeriswyl L, Andreasen D, Bernard N, Chen C, Cheo D, D'Andrade P, DeMayo M, Dennis L, et al: Evaluation of quantitative miRNA expression platforms in the microRNA quality control (miRQC) study. Nat Methods 11: 809-815, 2014

7. Siddiqui S, Zlock L, Jun D, Bonser LR, Finkbeiner W, Erle DJ and Woodruff PG: The role of miR-141 in IL-13-mediated mucus production. A40. Epithelial Regulation of Inflammation. American Thoracic Society, A1489-A1489, 2016. https://www. atsjournals.org/doi/abs/10.1164/ajrccm-conference.2016.193.1_ MeetingAbstracts.A1489.

8. Tamagawa S, Beder LB, Hotomi M, Gunduz M, Yata K, Grenman R and Yamanaka N: Role of miR-200c/miR-141 in the regulation of epithelial-mesenchymal transition and migration in head and neck squamous cell carcinoma. Int J Mol Med 33: 879-886, 2014

9. Liu CZ, Ye ZH, Ma J, He RQ, Liang HW, Peng ZG and Chen G: A qRT-PCR and gene functional enrichment study focused on downregulation of miR-141-3p in hepatocellular carcinoma and its clinicopathological significance. Technol Cancer Res Treat: Jan 1, 2017 (Epub ahead of print).

10. Kundu ST, Byers LA, Peng DH, Roybal JD, Diao L, Wang J, Tong P, Creighton CJ and Gibbons DL: The miR-200 family and the miR-183 96 182 cluster target Foxf2 to inhibit invasion and metastasis in lung cancers. Oncogene 35: 173-186, 2016.

11. Fan J, Jia L, Li Y, Ebrahim S, May-Simera H, Wood A, Morell RJ, Liu P, Lei J, Kachar B, et al: Maturation arrest in early postnata sensory receptors by deletion of the miR-183/96/182 cluster in mouse. Proc Natl Acad Sci USA 114: E4271-E4280, 2017.

12. Cui JY, Liang HW, Pan XL, Li D, Jiao N, Liu YH, Fu J, He XY, Sun GX, Zhang CL, et al: Characterization of a novel panel of plasma microRNAs that discriminates between Mycobacterium tuberculosis infection and healthy individuals. PLoS One 12: e0184113, 2017.
13. Zhou M, Yu G, Yang X, Zhu C, Zhang Z and Zhan X: Circulating microRNAs as biomarkers for the early diagnosis of childhood tuberculosis infection. Mol Med Rep 13: 4620-4626, 2016.

14. Livak KJ and Schmittgen TD: Analysis of relative gene expression data using real-time quantitative PCR and the 2(-Delta Delta C(T)) method. Methods 25: 402-408, 2001.

15. Lai CH, Luo CY, Lin PY, Kan CD, Chang RS, Wu HL and Yang YJ: Surgical consideration of in situ prosthetic replacement for primary infected abdominal aortic aneurysms. Eur J Vasc Endovasc Surg 42: 617-624, 2011.

16. Volinia S, Calin GA, Liu C-G, Ambs S, Cimmino A, Petrocca F, Visone R, Iorio M, Roldo C, Ferracin M, et al: A microRNA expression signature of human solid tumors defines cancer gene targets. Proc Natl Acad Sci USA 103: 2257-2261, 2006.

17. Zheng ZM and Wang X: Regulation of cellular miRNA expression by human papillomaviruses. Biochim Biophys Acta 1809: 668-677, 2011.

18. Li H, Kloosterman W and Fekete DM: MicroRNA-183 family members regulate sensorineural fates in the inner ear. J Neurosci 30: 3254-3263, 2010.

19. Yang M, Liu R, Li X, Liao J, Pu Y, Pan E, Yin L and Wang Y: miRNA-183 suppresses apoptosis and promotes proliferation in esophageal cancer by targeting PDCD4. Mol Cells 37: 873-880, 2014.

20. Zhao G, Wang B, Liu Y, Zhang JG, Deng SC, Qin Q, Tian K, Li X, Zhu S, Niu Y, et al: miRNA-141, downregulated in pancreatic cancer, inhibits cell proliferation and invasion by directly targeting MAP4K4. Mol Cancer Ther 12: 2569-2580, 2013.

21. Lee JW, Park YA, Choi JJ, Lee YY, Kim CJ, Choi C, Kim TJ, Lee NW, Kim BG and Bae DS: The expression of the miRNA-200 family in endometrial endometrioid carcinoma. Gynecol Oncol 120: 56-62, 2011.

22. Li J, Fu H, Xu C, Tie Y, Xing R, Zhu J, Qin Y, Sun Z and Zheng X: miR-183 inhibits TGF-beta1-induced apoptosis by downregulation of PDCD4 expression in human hepatocellular carcinoma cells. BMC Cancer 10: 354, 2010.

23. Du Y, Xu Y, Ding L, Yao H, Yu H,Zhou Tand Si J: Down-regulation of miR-141 in gastric cancer and its involvement in cell growth. J Gastroenterol 44: 556-561, 2009.

24. Kan CD, Lee HL and Yang YJ: Outcome after endovascular stent graft treatment for mycotic aortic aneurysm: A systematic review. J Vasc Surg 46: 906-912, 2007.

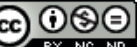

This work is licensed under a Creative Common Attribution-NonCommercial-NoDerivatives 4.0 International (CC BY-NC-ND 4.0) License. 